\title{
STUDENT ASSESSMENT AND MISCONCEPTIONS OF PHOTOSYNTHESIS: A NOTION OF SHIFTING PERSPECTIVE
}

\author{
Mustafa Kamal Nasution \\ STAIN Gajah Putih Takengon, Aceh Tengah, Aceh \\ Email: kamalnasution@gmail.com
}

\begin{abstract}
Abstrak. Photosynthesis topic is as a compulsory topic ineducation typically in the second year of secondary high school. There is perception of some students that the photosynthesis topic is difficult to learn by student. This paper will clarify questions such as what assessment does mean, what student misconceptions in photosynthesis are, how teachers deal with student misconceptions, and last, why do teachers, school and curriculum need to change perspective in assessment. Based on the discussion, there are some parts that need to be reaffirmed. The teachers should not just recognize assessment as a formal paper, but in term of perspective and classroom instruction. It should be actualized in teaching-learning that there is no judgement of right and wrong for students in leaning. Thus, dealing with student conception could be difficult for the teacher. The principal way is the teacher needs to be clear on the topic's planning and negotiate the meaning of all representations used in the classroom. Changing the type of assessments does not just simply mean changing teaching strategies or having appropriate types of assessment tool, but it could be a powerful source when it is integrated in the curriculum.
\end{abstract}

Key Words: photosynthesis, misconceptions, assessment.

\section{Introduction}

Photosynthesis has always been a compulsory subject in science education. This means as an educator or scientist, the subject is feasible to always be corrected in some aspects. In assessment part, there was an interesting assessment tasks in a web portal (Biodqc, 2011) measuring the university students' level of understanding in photosynthesis. The method used in the web portal could encourage our understanding as a biology teacher, particularly Aceh teacher, to look back on old chapter of our life. I realize that the content which was introduced when I was a student, is not similar with the content that the questions ask on this paper, it is much deeper. As a biology teacher, therefore, I argue that this assessment has a broad implication from the practical and theoretical perspectives.

There is perception of some students that the photosynthesis topic is difficult to learn (Tekkaya, Özkan, Sungur., 2001). Hence, this paper will discuss two questions; first, how to deal with the student misconception, particularly in the photosynthesis topic. Second, it will discuss why we need to change our perspective on assessment. In more detail, it will clarify questions such as what assessment does mean, what student misconceptions in photosynthesis are, how teachers deal with student misconceptions, and last, why do teachers, school and curriculum need to change perspective in assessment.

In Indonesia, the photosynthesis topic is as a compulsory topic in the second year of secondary high school. There are two samples of conceptual assessment tool at appendix 1 and 2 which. The questions and rubrics are designed for university student and teacher 
level and used as the main source of this paper. This paper will answer how changing the types of assessments could be a significant source when it is integrated in the curriculum.

\section{Assessment}

The term "assessment" is basically derived form assidere (Latin), meaning "to sit side by side" (Wiggins, 1993). Nowadays, the term "assessment" usually refers to the process of gathering information, with or without drawing conclusions or making inferences of information collected.

In the world of education, there are two types of assessment commonly used; formative and summative assessment. The common understanding of both assessments is from the time pointview. The formative is used in the ongoing teaching and learning process, while the summative is applied at the end of a lesson unit. Hubber (2011) stated that this is also a part of misconception in defining assessment because sometimes summative assessment does not apply at the end period of lesson only. The distinction might be from the perspective of purpose; the summative assessment is conducted if the teachers do not need to use the assessment result for the further teaching. Conversely, if the assessment result is used for the further teaching, it refers to formative assessment.

There are also other terms related to "assessment terminology" in Lorna (2003), namely assessment of, for, and as learning. In her article, she clarified that assessment of learning in classrooms is typically done at the end of a lesson unit. In other terms, it has the same idea with summative assessment. During the learning process, when the teacher gathers a wide range of information so that they can change the learning work for their students, it is called assessment for learning and similar with formative assessment. Lastly, assessment as learning occurs when the students personally are aware of what they are learning and use the feedback from this monitoring to make corrections, revisions, and even foremost changes in what they comprehend. Assessment as Learning is the eventual objective, where students becomes self-assessors (ibid 2003, pg.5).

One type of assessments used in this paper is conceptual assessment. Conceptual assessment is a new assessment term deriving from diagnostic assessment or preassessment. Both these terms principally aim to investigate the student's prior knowledge in order to design a further teaching strategy which possibly is compatible with their background. A conceptual assessment, therefore, is specifically used to diagnose what conceptions students have built in a particular topic.

Away from those terms, it is argued that children perceive a negative tension when the words come to their mind because it means they will be tested or evaluated. That is a conception of assessment in their mind and this is the way of education has revealed to them. Easley and Zwoyer (1975, p.25) made some interesting point that "if you can both listen to children and accept their answer not as things just to be judged right or wrong but as pieces of information which may reveal what child is thinking, you will have taken a giant step toward becoming a master teacher". In this chapter, therefore, it agrees that teachers should not just understand assessment as a form of paper, but also in the mindsets and classroom setting. The assessment term should be actualized in teachinglearning and there is no judgement of right and wrong for students in the learning process, there is no one teacher truth. 


\section{Student misconception}

While there are many misconceptions investigated in science literature for students, it could be less for university students and teacher. A 2007 conference in Colorado (USA) confirmed that conceptual assessment for university student or teacher level, specifically in biology, has attracted more attention than before. For Indonesian context where science subject is divided into smaller; biology, physics, and chemistry, this issue might be important. This chapter and below will focus typically on misconception in the photosynthesis lesson, as an instance, for the university students and teachers.

According to Tytler (nd) Students come into the class with a range of existing conceptions of the physical world and those conceptions might be different from the scientific view which scientists have constructed. In other words, they have built their own scientific view for years from their environment. This is the core of the problem. When a teacher or lecturer delivers some misconceptions to their students, and afterward some of the students become a teacher or lecturer and deliver it to other students, and again, the topic taught will be continuously transferred from generation to generation and become a cycle of misconception. In this problem, the teacher needs to understand what conceptions that the students have built.

\section{Conceptual assessment tools}

There are many ways and tools to identify student pre-conception. There might be also more types in other places than this chapter can gather. However, based on the medium of assessment, there are three coomon types of the tools; oral based tools, activity based tools, paper based tools, and internet based tools. The Table 1 bellow will subjectively give examples of each type.

Table 1. The conceptual assessment tools

\begin{tabular}{|l|l|}
\hline \multicolumn{1}{|c|}{ Type of Assessment Tools } & \multicolumn{1}{|c|}{ Examples } \\
\hline Oral based assessment tools & $\begin{array}{l}\text { Interview, direct classroom questions, } \\
\text { presentation, demonstration }\end{array}$ \\
\hline Paper based assessment tools & $\begin{array}{l}\text { multiple choice, rubrics, true-false questions, } \\
\text { simple questions, survey, mind map, drawing, }\end{array}$ \\
\hline Activity based assessment tools & $\begin{array}{l}\text { POE strategy (Predict, Observe, Explain), Post } \\
\text { box, Black box, }\end{array}$ \\
\hline $\begin{array}{l}\text { Internet/computer based assessment } \\
\text { tools }\end{array}$ & $\begin{array}{l}\text { Robograder-a mind map } \\
\text { http://ctools.msu.edu/ }\end{array}$ \\
\hline
\end{tabular}

Due to the assessment tools above, there is something that needs to be taken into account. The level of difficulties of examples above could range from sophisticated to simple. A teacher could create their own tools or use other sources for his specific purpose and context. For example, the questions and rubrics in Appendix 1 and 2, combining several types of representation are designed to diagnose the teacher or university student conceptions in photosynthesis.

It is predicted that some students will have some misconceptions of the topic. Each question in appendix 1, therefore, is designed to overcome a specific misconception 
based on the prediction. The question number one, for example, investigates students' pre-conception of photosynthesis in converting sunlight into the energy of element bond. Students might have other conceptions or even have no idea about principle of converting energy, or may just simply be distracted by colloquial words used in the question. In whatever possibilities, the question leads to some "scientific" conception that energy cannot be "used up" or converted into matter, but other different types of energy (Biodqc, 2011).

Despite all types of assessment above, one may be necessary for teachers is to acknowledge that all those tools could be comprised of many representations, such as words, diagram, graphs, numbers, gestures which may affect student understanding on the assessment (Tytler et al., 2010). It implies that to some extent the representation used in the assessment tools could be easy to understand or reversely, the student could be distracted by all symbols used in the tools. Hence, a good assessment tool relies heavily on offectiveness of the teacher's design.

\section{Effective Assessment}

The questions and rubric on the appendix 1 and 2 are the parts of universities project on Diagnostic Question Clusters to Improve Student Reasoning and Understanding in General Biology Courses in some American universities. At the first glance, the assessment tools seem designed sophisticatedly. However, it would be necessary for teacher to notice some indicators addressing the effectiveness of assessment. In Australia, the Victorian Curriculum and Learning Authorities suggested some outlines to create an affective assessment.

- Enhancing student performance is the core aims of assessment

- The assessment should be based on students learning

- The assessment involves clear purpose, standards, and criteria of procedures

- Validity, reliablity and consistency are used in the methodology

- Better to be ongoing rather than episodic

- Concerning outcomes, processes, reflection and feedback

- Reporting credibly to parents

Comparing the assessment samples and the effective assessment criteria, there are some possible inferences that can be made. First, using samples from other sources could be either relevant or not, depending on the teacher's need and understanding of their students, contexts, and culture. Second, for some teachers, integrating those criteria to their assessment might be difficult. It is suggested, therefore, to pick up some necessary parts and adjust to their own purpose and context.

Away from all inferences, it might be important for the teachers to consider that when an assessment involves the principles described above, it will be a key part of strategic planning, and become a potential resource of learning.

\section{Dealing with the student misconception}

After gathering all information from the students, the next step should be focused on how the teacher deal with all information gathered. The teacher might judge that all student conceptions are simply wrong when being compared with scientific conceptions. Tytler (2010) suggested that the task of science teacher is to find ways of providing pathways to support students to undergo major shifts in their perspective, through 
reasoning the capability of scientific way of looking the world. In the classroom setting, this idea might be extremely difficult for some teachers to design their pathway. The situation might be end up with just simply let the students know the answer, implanted scientific information to the children's head. However, this is the challenge for every teacher who is responsible for scientific development in the student's mind.

In this case, some principles suggested by many researchers are that the student should be guided to develop their own scientific representations (Greeno \& Hall 1997; Tytler, Peterson \& Prain 2006; Hubber, Tytler, \& Haslam 2010). The basic idea is the teacher needs to be clear on the topic's planning sequences that students are intended to learn and the range of representations. Thus, it becomes significant for a learning process if the teacher and student negotiate with the meaning in verbal, visual, mathematical, or even gestural representation in the classroom. Therefore, the teacher needs to select carefully the appropriate representations for addressing the particular need and be able to determine the effectiveness of achieving particular purpose (Tytler 2010).

Those are some strategies that a teacher can use to deal with student conception. It is believed that educational change is not just derived from the classroom point of view. Tytler (2010) mentioned in contemporary perspective science idea that the world of science has changing dramatically while of school science has not change so much. It is subjectively argued that the change in the world of education will only be started by the change of perspective.

\section{Shifting perspective and critics in assessment}

There has been a prolonged debate on assessment in education. Some people believe that assessment findings are significant for further instructions (NCREL 2011). Meanwhile Holt (1970, p.1) argued that "testing does more harm than good, at worst; it hinders, distorts, and corrupts the learning process". Will we have no agreement in this debate?

Newman, Griffin, \& Cole, (1989, p.87) suggested that "Instead of giving the children a task and measuring how well they do or how badly they fail, one can give the children the task and observe how much and what kind of help they need in order to complete the task successfully. In this approach the child is not assessed alone. Rather, the social system of the teacher and child is dynamically assessed to determine how far along it has progressed."

Recently, in the idea of contemporary science, Tytler (2010) asserted that there is a notion to shift from traditional to more social constructivist perspective. Shifting does not just refer to rational thinking, but also affective factor and classroom settings. The conceptual assessment is taking a big part of the changes in a classroom because the ideal purpose of it is not to design an appropriate teaching strategy, but also assessment tools.

Many perceptions in education might be constrained in perspective which implicitly states that changing the type of assessments could just simply mean changing teaching strategies or having appropriate types of assessment tools. However, if the assessment tools of types are changed, in a massive scale (national system scale) it could be a powerful source. In my country where has not been much changing in the assessment system this could mean a revolution of the Indonesian education.

In other countries, as an instance, in 1999, Singapore mathematic curriculum altered from traditional to solving curriculum - this is the first change. However, it did not work 
well before in 2001, the Singapore Ministry of education integrated the problem solving assessment, in the national curriculum (SingaporeMath 2011a). Since then, Singapore's mathematics seemed to go well and the assessment became a powerful energy in the Singapore mathematics education changes. Nowadays, the country has one of the best mathematics curriculum and mathematics achievements in the world. Many other countries send their teachers, learned the system, and adopt many text books from it.

Reorganizing assessment is expected to become a medium of seeking more suitable subjects for students, centring professional development for educators, restructuring curriculum, and enhancing teaching-learning process and materials (Hammond \& Wise 1985). In this spirit of changes, the student assessment is the core of many educational endeavours. The authorities expect that reform assessment, in terms of types, will affect educators to do in a different way (Linn, 1987).

\section{Conclusion}

There are at least three aims of this writing, firstly it attempts to clarify some misconceptions in photosynthesis, secondly, to decelerate the continuous misconceptions cycle in the photosynthesis subject, and lastly, to spread out the spirit of change in the world of assessment.

Based on the discussion above, there are some parts that need to be reaffirmed. The teachers should not just recognize assessment as a formal paper, but in term of perspective and classroom instruction. It should be actualized in teaching-learning that there is no judgement of right and wrong for students in leaning. Thus, dealing with student conception could be difficult for the teacher. The principal way is the teacher needs to be clear on the topic's planning and negotiate the meaning of all representations used in the classroom. Changing the type of assessments does not just simply mean changing teaching strategies or having appropriate types of assessment tool, but it could be a powerful source when it is integrated in the curriculum.

Furthermore, this paper recommends broadening investigations to determine first, the nature of each subject, and second, an appropriate assessment tools for each subject based on the nature.

\section{References}

Biodqc, 2011, Thinking Like A Biologist, Using Diagnostic Questions to Help Students Reason With Biological Principles. http://www.Biodqc.org, accessed on 18 January 2011.

Hammond, D.L \& Wise, A., 1985, Beyond standardization: state standards and school improvement. Elementary School Journal, 85, 315-36.

Easley and Zwoyer, 1975, In Crooks, T. 1988 The Impact of Classroom Evaluation Practices on Students, Review of Educational Research, 58 (4), p 469.

Greeno, J \& Hall, R., 1997, Practicing representation: learning with and about representation forms. Phi Delta Kappan, 78 (5), 361-368.

Holt, J., 1970, The tyranny of testing in The under achieving school, Penguin, London, pp.51-63.

Hubber, P., 2011, a class lecture: week 2. Deakin University, Australia. 
Hubber, P., Tytler, R., \& Haslam , F. 2010, Teaching and learning about force with a representational focus,: pedagogy and teacher change, Research in Science Education, 40(1), 5-28.

Linn, R., 1987, Accountability: The comparison of educational systems and the quality of test results. Educational Policy, 1(2): 181-198.

NCREL, 2011, Critical Issue: Integrating assessment and instruction in ways that support learning, http://www.ncrel.org/sdrs/areas/issues/methods/assment/as500.htm, accessed on 23 January 2011.

Newman, D., Griffin, P., \& Cole, M., 1989, The construction zone: Working for cognitive change in school. Cambridge, MA: Cambridge University Press.

SingaporeMath, 2011a, The Singapore Math story http://www.singaporemath.com/Singapore_Math_Story_s/10.htm, accessed on 18 January 2011.

SingaporeMath, 2011b, Singapore math fact sheet. http://www.singaporemaths.co.za/docs/sa_math_fact_sheet_june09.pdf, accessed on 18 January 2011.

Tekkaya, C., Özkan, Ö., Sungur, S., 2001, Biology concepts perceived as difficult by turkish high school students. Hacettepe Üniversitesi Ĕ̈itim Fakültesi Dergisi 21 : 145-150.

Tytler, R., nd, Constructivist and socio cultural views of teaching and learning (draft, in press) in G. Venville \& V. Dawson (Eds), The Art of Teaching Science, Perth: Alen and Unwin 